\title{
Author Correction: Longitudinal unzipping of 2D transition metal dichalcogenides
}

Suchithra Padmajan Sasikala (1), Yashpal Singh (1), Li Bing, Taeyoung Yun, Sung Hwan Koo, Yousung Jung (1) \& Sang Ouk Kim (1)

Correction to: Nature Communications https://doi.org/10.1038/s41467-020-18810-0, published online 6 October 2020.

The original version of this Article contained an error in the author's affiliations.

The affiliation of Yousung Jung with Department of Chemical and Biomolecular Engineering, KAIST, Daejeon 34141, Republic of Korea was inadvertently omitted. Yousung Jung was incorrectly associated with Graduate School of EEWS, KAIST, Daejeon 34141, Republic of Korea.

The original version of this Article omitted the following from the Acknowledgements:

"Y.S. acknowledges generous financial support from C1 Gas Refinery R\&D Center (NRF- 2019M3D3A1A01069099)."

This has now been corrected in both the PDF and HTML versions of the Article.

Published online: 27 October 2020

\footnotetext{
(c) (i) Open Access This article is licensed under a Creative Commons Attribution 4.0 International License, which permits use, sharing, adaptation, distribution and reproduction in any medium or format, as long as you give appropriate credit to the original author(s) and the source, provide a link to the Creative Commons license, and indicate if changes were made. The images or other third party material in this article are included in the article's Creative Commons license, unless indicated otherwise in a credit line to the material. If material is not included in the article's Creative Commons license and your intended use is not permitted by statutory regulation or exceeds the permitted use, you will need to obtain permission directly from the copyright holder. To view a copy of this license, visit http://creativecommons.org/licenses/by/4.0/.
}

(๑) The Author(s) 2020 